\title{
Período Crítico de Competição de Plantas Daninhas com a Cultura do Trigo ${ }^{1}$
}

\author{
Critical Period for Weed Competition with Wheat
}

\begin{abstract}
AGOSTINETTO, D. ${ }^{2}$, RIGOLI, R.P. ${ }^{3}$, SCHAEDLER, C.E. ${ }^{4}$, TIRONI, S.P. ${ }^{5}$ e SANTOS, L.S. ${ }^{5}$
RESUMO - Na cultura do trigo, diversos fatores limitam a sua produtividade, dentre os quais se destaca a competição imposta por plantas daninhas. O objetivo deste trabalho foi determinar o período crítico de interferência das plantas daninhas na cultura do trigo e os efeitos da competição em variáveis morfológicas e nos componentes da produtividade. $\mathrm{O}$ experimento foi conduzido a campo, no ano de 2006, no Centro Agropecuário da Palma, Capão do Leão/RS. Os fatores testados foram períodos de convivência e controle das plantas daninhas na cultura do trigo, cultivar FUNDACEP 52. Os períodos de convivência e/ou controle foram de: $0,7,14,21,28,35,42$ e 126 dias após a emergência (DAE). Os resultados obtidos referentes às variáveis determinadas no final de cada período de controle ou convivência e por ocasião da colheita demonstraram que os componentes da produtividade do trigo não foram influenciados pela competição com plantas daninhas e que medidas efetivas de controle devem ser adotadas no período entre 12 e 24 dias após a emergência.
\end{abstract}

Palavras-chave: convivência, controle, interferência, produtividade.

\begin{abstract}
Several factors limit wheat crop yield, with competition imposed by weed plants being the most outstanding. The objective of this study was to determine the critical period of weed interference in wheat crop and the effects of competition on morphological variables and yield components. This field experiment was carried out at Centro Agropecuário da Palma, Capão do Leão, RS, Brazil. Factors tested were periods of coexistence and weed plant control in FUNDACEP 52 wheat cultivar. Periods of coexistence and/or control were: $0,7,14,21,28,35$, 42 and 126 days after emergence (DAE). Results obtained for variables at the end of each control period or coexistence, and at harvesting, showed that wheat yield components were not affected by competition with weed plants and that effective control measures should be taken between 12 and 24 days after emergence.
\end{abstract}

Keywords: coexistence, control, interference, yield.

\section{INTRODUÇÃO}

A competição entre plantas é parte fundamental na ecologia dos vegetais e ocorre onde duas ou mais plantas utilizam ou retiram recursos para seu crescimento e desenvolvimento, os quais estão limitados no ecossis- tema comum, ou seja, uma planta inibe outra pelo consumo de recursos limitados. Quanto maior a semelhança entre as espécies, mais intensa será a competição por recursos do meio (Radosevich et al., 1997). Os diferentes nichos ocupados por plantas daninhas e culturas geralmente não são grandes o bastante

1 Recebido para publicação em 16.10.2007 e na forma revisada em 27.3.2008.

2 Eng ${ }^{\circ}-$ Agr $^{\circ}$, Dr., Prof. da Faculdade de Agronomia da FAEM/UFPel, bolsista do CNPq, Caixa Postal, 354, 96010-900, Pelotas/ RS, <dirceu_agostinetto@ufpel.tche.br>; ${ }^{3}$ Bióloga, Mestranda do Programa de Pós-Graduação em Fitossanidade, FAEM/UFPel; ${ }^{4}$ Eng $^{\mathrm{o}}$-Agr ${ }^{\circ}$, Mestrando do Programa de Pós-Graduação em Fitossanidade, FAEM/UFPel; ${ }^{5}$ Aluno do curso de graduação em Agronomia, FAEM/UFPel. 
para permitir a máxima produtividade da cultura sem que ocorra alguma intervenção humana para controle das plantas daninhas.

Existem duas teorias de competição: a de Grime e a de Tilman (Radosevich et al., 1997). A primeira propõe que as plantas competidoras possuem elevada velocidade de utilização dos recursos do meio, indisponibilizando-os para seus vizinhos, bem como elevada taxa de crescimento relativo. A segunda teoria sugere que as plantas competidoras necessitam de menos recursos, ou seja, apresentam capacidade de sobreviver em ambientes desfavoráveis.

Em trigo, diversos fatores limitam a produtividade da cultura, dentre os quais se destaca a competição imposta por plantas daninhas. A intensidade da competição normalmente é avaliada por meio de decréscimos de produção e/ou pela redução no crescimento da planta cultivada, como respostas à competição pelos recursos de crescimento disponiveis no ambiente $\left(\mathrm{CO}_{2}\right.$, água, luz e nutrientes). Entretanto, os resultados da relação planta daninha-cultura dependem, também, de outros fatores específicos, que incluem variações meteorológicas, composição e população das espécies presentes e práticas de manejo.

As espécies daninhas mais problemáticas na triticultura do Rio Grande do Sul são Raphanus raphanistrum, Raphanus sativus, Lolium multiflorum e Avena strigosa. A competição entre plantas que ocupam o mesmo nicho inicia-se muito cedo, afetando a dominância apical. Esta inibe o crescimento de órgãos laterais, e o grau de inibição depende da espécie, do ambiente e da idade da planta (Almeida \& Mundstock, 2001). Os efeitos da qualidade da luz sobre o crescimento e o desenvolvimento manifestam-se precocemente sobre as plantas e, antes mesmo que ocorra qualquer redução na radiação fotossinteticamente ativa, os sinais de luz percebidos pelo fitocromo desempenham função de detecção do nível de competição que as plantas irão encontrar, especialmente quando a competição tende a ser intensa. As plantas percebem que estão sendo sombreadas quando a relação entre a luz vermelha e a vermelho-distante é reduzida, favorecendo, nessa situação, o alongamento do colmo em detrimento do crescimento generalizado (Larcher, 2000).
Quanto maior a população da comunidade infestante, maior será a quantidade de indivíduos que disputam os recursos do meio e mais intensa será a competição com a cultura. Além disso, espécies morfológica e fisiologicamente próximas apresentam exigências semelhantes em relação aos recursos, tornando ainda mais intensa a competição (Silva \& Durigan, 2006).

O grau de competição entre plantas daninhas e cultura pode ser alterado em função do período em que a comunidade estiver disputando determinado recurso. No início do ciclo de desenvolvimento, a cultura e as plantas daninhas podem conviver por determinado período sem que ocorram danos à produtividade da cultura (Brighenti et al., 2004). Nessa fase, denominada período anterior à interferência (PAI), o meio é capaz de fornecer os recursos de crescimento necessários à comunidade (Velini, 1992).

O segundo período, denominado de período total de prevenção da interferência (PTPI), é aquele, a partir da emergência, quando a cultura deve crescer livre da presença de plantas daninhas para que sua produtividade não seja alterada (Brighenti et al., 2004). A partir desse periodo, as plantas daninhas que se instalarem não irão interferir de maneira a reduzir a produtividade da cultura, pois esta já apresenta capacidade de suprimir as plantas concorrentes.

O terceiro período, denominado de período crítico de prevenção da interferência (PCPI), corresponde à diferença entre o PAI e o PTPI, sendo a fase em que as práticas de controle deveriam ser efetivamente adotadas para prevenir perdas na produtividade das culturas (Evans et al., 2003).

Os efeitos da interferência são irreversíveis, não havendo recuperação do desenvolvimento ou da produtividade após a retirada do estresse causado pela presença das plantas daninhas (Kozlowski, 2002). Assim, em termos de manejo de plantas daninhas, o PAI tornase o período de maior importância, a partir do qual a produtividade é significativamente afetada.

Estudos conduzidos em outras culturas anuais demonstram que a duração de cada período (em dias) variou com a cultura e as 
plantas daninhas presentes na área. Entretanto, para a cultura do trigo, em termos de Brasil, são desconhecidas informações que descrevam esses períodos de competição com as plantas daninhas.

As informações sobre os períodos de competição (PC) em trigo podem auxiliar na decisão do momento da adoção de medidas de manejo e/ou de controle. O principal método de controle de plantas daninhas utilizado pelos triticultores é o químico. O conhecimento do PC poderá reduzir o número de aplicações de herbicidas, melhorar a eficiência de controle e, ainda, reduzir a possivel contaminação ambiental e o surgimento de plantas daninhas resistentes a herbicidas.

A hipótese deste trabalho é de que o período crítico de prevenção da interferência das plantas daninhas inicia-se aos 15 e termina aos 36 dias após a emergência (DAE) do trigo; quanto maior o periodo de convivência das plantas daninhas com a cultura, maiores são as perdas na produtividade de grãos. Assim, o objetivo deste estudo foi determinar o período crítico de interferência das plantas daninhas na cultura do trigo e os efeitos da competição em variáveis morfológicas e nos componentes da produtividade.

\section{MATERIAL E MÉTODOS}

O experimento foi conduzido a campo no Centro Agropecuário da Palma (CAP), da Universidade Federal de Pelotas (UFPel), no município de Capão do Leão-RS, em solo classificado como Argissolo Vermelho-Amarelo, de textura franco-arenosa, pertencente à unidade de mapeamento Pelotas (Embrapa, 1999). Antecedendo a semeadura, foi realizada dessecação da cobertura vegetal de toda a área, a fim de eliminar as plantas daninhas presentes e uniformizar a emergência delas e da cultura.

O delineamento experimental utilizado foi em blocos ao acaso, com três repetições, e cada unidade experimental ocupou área de $7,2 \mathrm{~m}^{2}$ $(4,7 \times 1,53 \mathrm{~m})$. A semeadura do trigo foi realizada no dia 29 de junho de 2006, utilizando-se semeadora regulada com espaçamento entrelinhas de $17 \mathrm{~cm}$ e distribuição de 415 sementes viáveis por $\mathrm{m}^{2}$, o que permitiu estabelecer população média de 288 plantas $\mathrm{m}^{-2}$. O cultivar de trigo utilizado foi o FUNDACEP 52, de ciclo precoce a médio.

A adubação foi feita segundo análise de solo, utilizando-se $285 \mathrm{~kg} \mathrm{ha}^{-1}$ de N-P-K, da fórmula 6-14-12, seguindo-se as recomendações técnicas para a cultura (Informações, ... 2006). $\mathrm{Na}$ adubação de cobertura utilizaram-se $80 \mathrm{~kg} \mathrm{ha}^{-1}$ de nitrogênio, na forma de uréia, a qual foi fracionada em duas aplicações: no início do afilhamento e no início do alongamento do colmo. Preventivamente ao aparecimento de doenças, realizaram-se três aplicações de fungicida durante a condução do experimento.

O experimento foi composto por dois fatores: períodos de convivência e períodos de controle das plantas daninhas com a cultura do trigo. No período de convivência, a cultura foi mantida na presença de plantas daninhas por períodos iniciais crescentes de: $0,7,14,21$, 28, 35, 42 e 126 dias após a emergência (DAE), a partir dos quais foram controladas. No período de controle, a cultura foi mantida livre de plantas daninhas nos mesmos períodos descritos anteriormente, e as espécies infestantes emergidas após esses intervalos não foram mais controladas. A remoção das plantas daninhas foi realizada com capinas manuais em cada período. As espécies de maior ocorrência na área foram azevém e nabo, em populações médias de 24 e 228 plantas $\mathrm{m}^{2}$, respectivamente.

No final de cada período de convivência ou de controle, foi quantificada a matéria seca da parte aérea (MS) da cultura (MSC) e das plantas daninhas (MSPD) e determinada a estatura da cultura (EC). Para determinação da MSC, realizou-se a coleta de plantas em $1 \mathrm{~m}$ de fileira de cada unidade experimental. Já para quantificação da MSPD, utilizou-se quadrado com área de $0,25 \mathrm{~m}^{2}$. As amostras foram secas em estufa a $60^{\circ} \mathrm{C}$ até massa constante. A quantificação da EC foi determinada com auxílio de régua graduada, escolhendo-se, aleatoriamente, dez plantas por parcela, tomandose a medida desde o nível do solo até o ápice delas (com o limbo foliar distendido).

No final do ciclo da cultura foram analisados estatura, número de colmos por área (NCA), produtividade biológica aparente (PBA), índice de colheita aparente (ICA), componentes da produtividade de grãos [peso hectolitro $(\mathrm{PH})$, antécios por espiga (AE), grãos por espiga (GE) e 
massa de mil grãos (MG)] e produtividade de grãos. Para obtenção da PBA foram coletadas plantas em área de $0,25 \mathrm{~m}^{2}$ e secas em estufa a $60{ }^{\circ} \mathrm{C}$ até massa constante, sendo então pesadas. A MSC, incluindo espigas e grãos, forneceu a PBA. A divisão da matéria seca dos grãos pela produção biológica aparente forneceu o ICA (expresso em porcentagem). O NCA foi determinado através de contagem na mesma área destinada à PBA. No final do ciclo foram realizadas as determinações dos números de $\mathrm{AE}$ e GE, em dez plantas escolhidas aleatoriamente em cada parcela.

A colheita do trigo foi realizada 126 dias após a emergência (DAE). A produtividade de grãos $\left(\mathrm{kg} \mathrm{ha}^{-1}\right)$ foi determinada em área de $3,57 \mathrm{~m}^{-2}$. Após a determinação da umidade dos grãos, a massa das amostras foi padronizada para $13 \%$. Posteriormente, foi determinado o PH e o MG, obtidos a partir da massa de 600 grãos separados aleatoriamente do total de grãos colhidos na área útil de cada unidade experimental.

Os dados referentes a MSC, MSPD e EC, obtidos no final de cada periodo de controle ou convivência, e os de EC, NCA, PBA e ICA, por ocasião da colheita, foram submetidos à análise de variância. Quando a probabilidade F foi significativa, as médias foram comparadas pelo teste $t(p \leq 0,05)$ ou Duncan $(p \leq 0,05)$.

Os dados das demais variáveis foram submetidos à análise de variância e, sendo significativos, as médias dos tratamentos foram

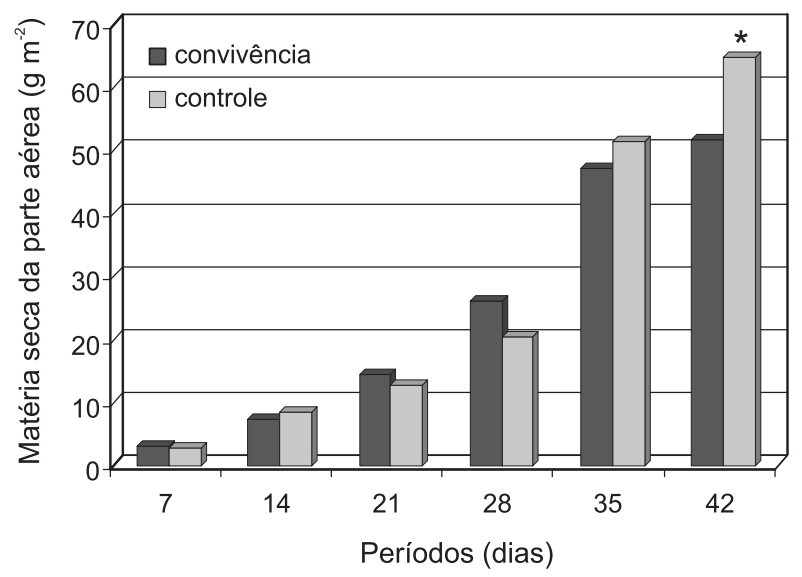

Figura 1 - Matéria seca da parte aérea do trigo acumulada em cada período de controle ou convivência com plantas daninhas. CAP/UFPel, Capão do Leão-RS, 2006. * Significativo pelo teste $\mathrm{t}(\mathrm{p}<0,05)$.

Planta Daninha, Viçosa-MG, v. 26, n. 2, p. 271-278, 2008 comparadas, aplicando-se o teste de Duncan $(p \leq 0,05)$ entre os periodos e o teste $t(p \leq 0,05)$ para comparar as médias dentro de cada periodo com controle ou convivência. Para a variável produtividade de grãos, os dados foram submetidos à análise de regressão pelo modelo logísti$c o$, através da equação $\mathrm{y}=\mathrm{y}_{0}+\mathrm{a} /\left(1+\left(\mathrm{x} / \mathrm{x}_{0}\right)^{\mathrm{b}}\right.$, em que: $\mathrm{y}=$ produtividade de grãos; $\mathrm{y}_{0}=$ produtividade minima obtida na testemunha infestada; $\mathrm{a}=$ valor máximo menos o valor mínimo obtido na testemunha limpa estimado pelo modelo; $\mathrm{x}=$ número de dias após a emergência da cultura; $\mathrm{x}_{0}=$ número de dias em que ocorre $50 \%$ da redução; e b = declividade da curva.

O periodo crítico de interferência das plantas daninhas foi estimado subtraindo-se 5\% da média de produtividade nas parcelas mantidas sem convivência de plantas daninhas durante todo o ciclo. Esse valor foi considerado como o custo da adoção do controle químico.

\section{RESULTADOS E DISCUSSÃO}

Os resultados referentes às variáveis determinadas no final de cada periodo de controle ou convivência demonstraram haver diferenças significativas para a MSC somente aos 42 $\mathrm{DAE}$, quando o período de controle foi superior ao de convivência (Figura 1). Comportamento semelhante foi observado para a estatura de planta aos 42 DAE; no entanto, as maiores médias foram constatadas para as plantas mantidas em convivência (Figura 2). Esses resultados podem decorrer da influência da qualidade

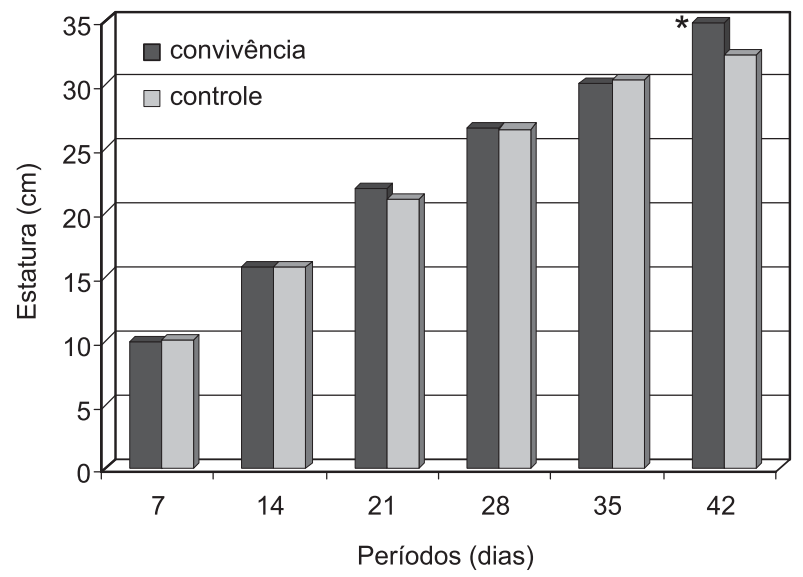

Figura 2 - Estatura de plantas de trigo em cada período de controle ou convivência com as plantas daninhas. CAP/ UFPel, Capão do Leão-RS, 2006. * Significativo pelo teste $\mathrm{t}(\mathrm{p}<0,05)$. 
da luz sobre o crescimento e desenvolvimento do trigo em função da competição das plantas daninhas presentes nas unidades experimentais.

A qualidade da luz pode desempenhar papel crítico na determinação da emissão, desenvolvimento e sobrevivência dos afilhos, sendo modificada precocemente em comunidades de plantas (Almeida \& Mundstock, 2001). Esses dois processos estão relacionados, podendo afetar a sobrevivência dos afilhos, os quais participam como parte dos componentes da produtividade das plantas e como prováveis supridores de assimilados ao colmo principal (Merotto Jr., 1995). Da mesma forma, a estatura de planta é uma característica que pode ser influenciada pela competição, dependendo da cultura e do hábito de crescimento das plantas daninhas, reduzindo a penetração da luz no dossel e refletindo em perdas na produtividade (Duarte et al., 2002).

Devido à infestação de nabo e azevém nas unidades experimentais, as plantas de trigo acumularam menos matéria seca no período de convivência, possivelmente pela menor emissão e sobrevivência dos afilhos; contudo, apresentaram maior estatura no período de convivência, o que pode decorrer do fato de a conversão de assimilados ter sido revertida ao colmo principal. Essa estratégia geralmente é utilizada por plantas cultivadas quando a luz é o principal recurso limitado na comunidade (Almeida \& Mundstock, 2001).

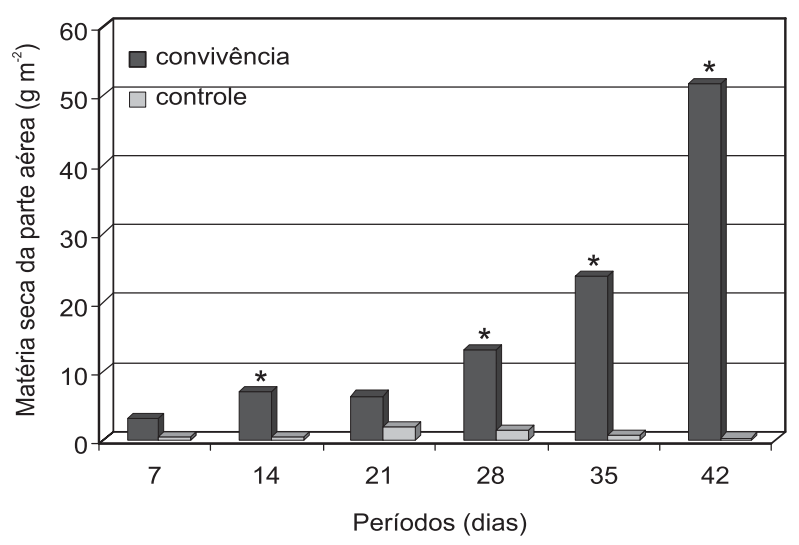

Figura 3 - Matéria seca da parte aérea de plantas de nabo presentes em cada período de controle ou convivência com o trigo. CAP/UFPel, Capão do Leão-RS, 2006. * Significativo pelo teste $\mathrm{t}(\mathrm{p}<0,05)$.
A produção de MS pelo nabo foi superior nos periodos de convivência, comparativamente aos controles, para $14,28,35$ e $42 \mathrm{DAE}$ (Figura 3). O resultado pode decorrer do fechamento das entrelinhas da cultura, diminuindo a incidência de luz, causando redução de reinfestação nos períodos mantidos com controle. Nos periodos mantidos com convivência, as plantas daninhas demonstraram habilidade competitiva superior, uma vez que o acúmulo de MS tendeu a aumentar após estabilização de sua população, demonstrando que sua germinação foi restringida após determinada fase do ciclo da cultura.

Quanto ao acúmulo de MS do azevém, o período de convivência foi superior ao de controle apenas aos 35 e 42 DAE (Figura 4). Isso, possivelmente, ocorreu porque a população das plantas de azevém na área era baixa e o controle cultural exercido pelo trigo, sombreando as entrelinhas, impediu o estabelecimento de novas plantas. Outra explicação relaciona-se com a habilidade competitiva superior do trigo em relação ao azevém, uma vez que ambos pertencem à mesma família, comparativamente ao nabo.

O acúmulo total de MS pode ser considerado um indicador mais confiável do que a população de plantas daninhas, no tocante ao grau de competição imposto à cultura (Brighenti et al., 2004). À medida que aumenta a população e ocorre o desenvolvimento das plantas daninhas, especialmente daquelas que

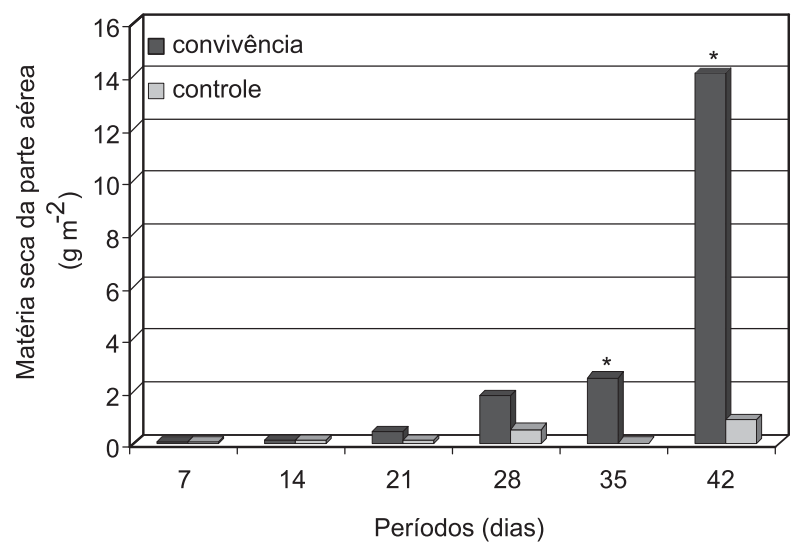

Figura 4 - Matéria seca da parte aérea de plantas de azevém presentes no final de cada período de controle ou convivência com o trigo. CAP/UFPel, Capão do Leão-RS, 2006. * Significativo pelo teste $\mathrm{t}(\mathrm{p}<0,05)$.

Planta Daninha, Viçosa-MG, v. 26, n. 2, p. 271-278, 2008 
germinaram e emergiram no início do ciclo da cultura, intensifica-se a competição inter e intra-específica, de forma que as plantas daninhas de maior estatura tornam-se dominantes, ao passo que as menores são suprimidas, inclusive pela própria cultura, ou morrem (Radosevich et al., 1997).

Para as variáveis EC nos períodos de controle ou convivência e NCA nos períodos de controle, determinadas no final do ciclo, não se verificaram diferenças significativas (Tabela 1). Já para NCA nos períodos de convivência, constatou-se diferença somente para convivência durante todo o ciclo da cultura, em relação aos períodos iniciais. Isso pode dever-se ao fato de a competição do trigo com as plantas daninhas até o final do ciclo ter sido intensa e, conseqüentemente, formaram-se menores números de afilhos e de colmos. Para ambas as variáveis, não se verificaram diferenças entre períodos de controle ou de convivência.

As variáveis $\mathrm{AE}, \mathrm{GE}, \mathrm{PG}$ e $\mathrm{PH}$ não apresentaram diferenças entre os tratamentos mantidos com controle ou convivência (dados não apresentados). Acredita-se que essas variáveis não sofreram efeitos diferenciais impostos pelas condições de competição com as plantas

Tabela 1 - Efeito de períodos de controle ou de convivência de plantas daninhas com a cultura do trigo na estatura e no número de colmos no final do ciclo. CAP/UFPel, Capão do Leão-RS, 2006

\begin{tabular}{|c|c|c|c|c|}
\hline \multirow{2}{*}{$\begin{array}{c}\text { Período } \\
(\text { dia })\end{array}$} & \multicolumn{2}{|c|}{ Estatura $(\mathrm{cm})$} & \multicolumn{2}{c|}{ Colmo $\left(\mathrm{n}^{\mathrm{o}} \mathrm{m}^{-2}\right)$} \\
\cline { 2 - 5 } & Controle & Convivência & Controle & Convivência \\
\hline 0 & ${ }^{\mathrm{ns}} 90^{\mathrm{ns}}$ & ${ }^{\mathrm{ns}} 86$ & ${ }^{\mathrm{ns}} 385^{\mathrm{ns}}$ & $\mathrm{a} 356$ \\
\hline 7 & $89^{\mathrm{ns}}$ & 91 & $399^{\mathrm{ns}}$ & $\mathrm{a} 424$ \\
\hline 14 & $88^{\mathrm{ns}}$ & 88 & $391^{\mathrm{ns}}$ & $\mathrm{a} 405$ \\
\hline 21 & $90^{\mathrm{ns}}$ & 90 & $388^{\mathrm{ns}}$ & $\mathrm{a} 423$ \\
\hline 28 & $91^{\mathrm{ns}}$ & 88 & $423^{\mathrm{ns}}$ & $\mathrm{a} 380$ \\
\hline 35 & $88^{\mathrm{ns}}$ & 90 & $397^{\mathrm{ns}}$ & $\mathrm{a} 340$ \\
\hline 42 & $89^{\mathrm{ns}}$ & 88 & $423^{\mathrm{ns}}$ & $\mathrm{a} 443$ \\
\hline 126 & $86^{\mathrm{ns}}$ & 88 & $337^{\mathrm{ns}}$ & $\mathrm{b} 237$ \\
\hline Média & 89 & 89 & 392 & 376 \\
\hline CV (\%) & 2,5 & 3,4 & 10,6 & 14,5 \\
\hline
\end{tabular}

${ }^{1 /}$ Médias antecedidas por letras distintas, comparadas na coluna, diferem pelo teste de Duncan $(\mathrm{p}<0,05)$ ou nas linhas, para cada variável, pelo teste $\mathrm{t}(\mathrm{p}<0,05)$. daninhas em razão de a qualidade da luz modular o alongamento do colmo principal e devido à capacidade do trigo em emitir e produzir afilhos férteis. Como os afilhos representam drenos de assimilados do colmo principal, a estratégia das plantas foi suprimir a emissão destes ou abortar os existentes, revertendo a alocação de assimilados para as estruturas reprodutivas, garantindo a qualidade das espigas e dos grãos.

A PBA é um indicativo da produção acumulada de matéria seca das plantas durante o ciclo de desenvolvimento da cultura e de quanto dela é convertido para produção de grãos (Donald, 1962). No experimento, somente foram observadas diferenças na PBA da convivência de plantas daninhas durante todo o ciclo de desenvolvimento, em relação aos períodos iniciais (Tabela 2 ).

Os estresses enfrentados durante o desenvolvimento da cultura - como o que decorre da competição de plantas daninhas - podem alterar a quantidade de matéria seca acumulada pelas plantas. A maior competição, resultante da presença das plantas daninhas na produtividade do trigo, foi confirmada pelo efeito observado na eficiência de conversão da PBA acumulada pelas plantas para produção de

Tabela 2 - Efeito de períodos de controle ou de convivência de plantas daninhas com a cultura do trigo na produtividade biológica e no índice de colheita. CAP/UFPel, Capão do Leão-RS, 2006

\begin{tabular}{|c|c|c|c|c|}
\hline \multirow{2}{*}{$\begin{array}{c}\text { Período } \\
(\text { dia })\end{array}$} & $\begin{array}{c}\text { Produtividade biológica } \\
\left(\mathrm{kg} \mathrm{ha}^{-1}\right)\end{array}$ & \multicolumn{2}{|c|}{$\begin{array}{r}\text { Índice de colheita } \\
(\%)\end{array}$} \\
\cline { 2 - 5 } & $\begin{array}{c}\text { Controle } \\
\text { Convivência }^{\text {Controle }}\end{array}$ & Convivência \\
\hline 0 & ${ }^{\mathrm{ns}} 9660^{\mathrm{ns}}$ & $\mathrm{a} 9737$ & ${ }^{\mathrm{ns}} 44,1^{\mathrm{ns}}$ & $\mathrm{a} 44,7$ \\
\hline 7 & $11013^{\mathrm{ns}}$ & $\mathrm{a} 11925$ & $44,8^{\mathrm{ns}}$ & $\mathrm{a} 45,8$ \\
\hline 14 & $10373^{\mathrm{ns}}$ & $\mathrm{a} 11083$ & $47,9^{\text {ns }}$ & $\mathrm{a} 46,6$ \\
\hline 21 & $10347^{\mathrm{ns}}$ & $\mathrm{a} 11252$ & $46,3^{\mathrm{ns}}$ & $\mathrm{a} 45,7$ \\
\hline 28 & $11741^{\mathrm{ns}}$ & $\mathrm{a} 10268$ & $44,7^{\mathrm{ns}}$ & $\mathrm{a} 45,1$ \\
\hline 35 & $11203^{\mathrm{ns}}$ & $\mathrm{a} 9355$ & $44,1^{\mathrm{ns}}$ & $\mathrm{a} 45,8$ \\
\hline 42 & $11266^{\mathrm{ns}}$ & $\mathrm{a} 11831$ & $45,4^{\mathrm{ns}}$ & $\mathrm{a} 45,6$ \\
\hline 126 & $9471^{*}$ & $\mathrm{~b} 6716$ & $45,2^{*}$ & $\mathrm{~b} 30,9$ \\
\hline Média & 10634 & 10270 & 45,3 & 43,7 \\
\hline CV (\%) & 10,1 & 14,1 & 3,2 & 4,9 \\
\hline
\end{tabular}

${ }^{1 /}$ Médias antecedidas por letras distintas, comparadas na coluna, diferem pelo teste de Duncan $(\mathrm{p}<0,05)$ ou nas linhas, para cada variável, pelo teste $t(p<0,05)$. 
grãos (ICA). O ICA foi reduzido quando a cultura foi mantida em convivência com as plantas daninhas durante todo o ciclo dela, mas não houve diferenças nos períodos de controle (Tabela 2). A comparação entre períodos de controle ou convivência, para as variáveis PBA e ICA, mostrou diferença somente no último periodo (Tabela 2).

Os tratamentos em que o trigo foi mantido por periodos iniciais crescentes na ausência de plantas daninhas permitiram calcular o período em que estas podem emergir e infestar a cultura sem que haja perdas na produtividade (Figura 5). Considerando como de 5\% o custo de controle químico, foram necessários 12 dias para que o trigo apresentasse perdas superiores aos custos de controle periodo que corresponde ao PAI. O PTPI, calculado pelo modelo, foi de $24 \mathrm{DAE}$. Assim, o período em que as práticas de controle devem ser efetivamente adotadas (PCPI) foi dos 12 aos 24 DAE.

Neste trabalho, optou-se por determinar o período crítico de prevenção da interferência somente em DAE e não por estádio de desenvolvimento da cultura. Essa metodologia pode não ser a mais adequada, pelo fato de que o estádio fenológico é que define os tratos culturais nas culturas. No entanto, a definição do período de convivência das plantas daninhas pelo estádio fenológico também não é totalmente apropriada, pois leva em consideração

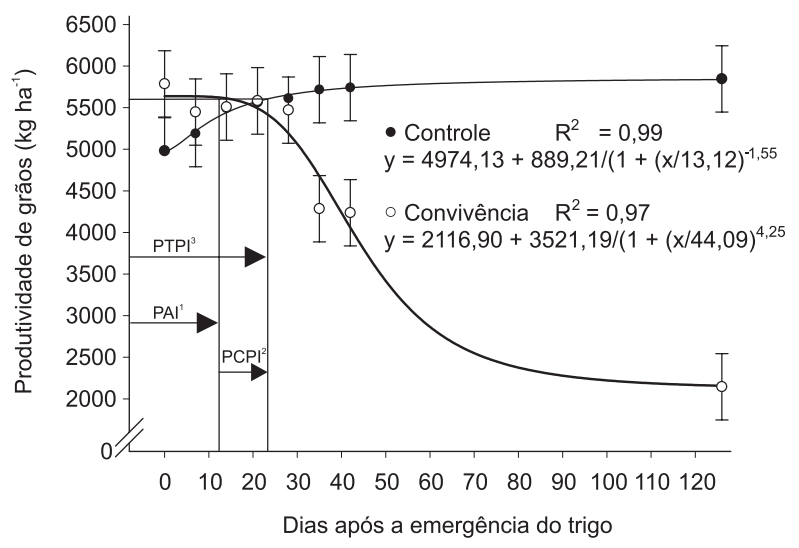

Figura 5 - Definição dos períodos de controle e de convivência de plantas de azevém e nabo na cultura do trigo, com base na produtividade de grãos. CAP/UFPel, Capão do LeãoRS, 2006. ${ }^{1}$ Período anterior à interferência; ${ }^{2}$ Período crítico de prevenção da interferência; ${ }^{3}$ Período total de prevenção da interferência. apenas um dos componentes do sistema - a cultura, deixando de considerar as espécies daninhas (Vidal et al., 2005). Segundo os autores, a cultura do milho, quando semeada em período frio, pode levar até 50 DAE para atingir o estádio $V_{3}$. Entretanto, na comunidade infestante da cultura poderá haver espécies adaptadas a se desenvolverem adequadamente nessas condições, de forma que, quando a cultura estiver no referido estádio de desenvolvimento, as plantas daninhas já terão dominado o nicho, comprometendo seriamente a produtividade de grãos da cultura.

A determinação do PCPI em trigo e em outras culturas é fundamental para manejo correto das plantas daninhas, a fim de se evitarem perdas e uso desnecessário de herbicidas. Contudo, o estabelecimento preciso desse período é complexo, pois fatores como época de semeadura e população de plantas da cultura, dose e épocas de aplicação da adubação nitrogenada e espécies e populações de plantas daninhas presentes na área influenciam consideravelmente os resultados, ocasionando diferenças em locais e anos distintos.

Conclui-se que o crescimento em estatura da cultura do trigo no final do período de avaliação, nos tratamentos com convivência, indica que o recurso luz pode ser o limitante na competição do trigo com o azevém e o nabo; os componentes da produtividade do trigo não foram influenciados pela competição do azevém e do nabo; e medidas de controle das plantas daninhas em trigo devem ser adotadas no período entre 12 e 24 dias após a emergência da cultura.

\section{LITERATURA CITADA}

ALMEIDA, L. A.; MUNDSTOCK, C. M. A qualidade da luz afeta o afilhamento em plantas de trigo, quando cultivadas sob competição. Ci. Rural, v. 31, n. 3, p. 401408, 2001.

BRIGHENTI, A. M. et al. Períodos de interferência de plantas daninhas na cultura do girassol. Planta Daninha, v. 22, n. 2, p. 251-257, 2004.

DONALD, C. M. In search of yield. J. Aust. Inst. Agric. Sci., v. 28, n. 3, p. 171-178, 1962.

DUARTE, N. F.; SILVA, J. B.; SOUZA, I. F. Competição de plantas daninhas com a cultura do milho no município de Jaci, MG. Ci. Agr., v. 26, n. 5, p 983-992, 2002. 
EMPRESA BRASILEIRA DE PESQUISA

AGROPECUÁRIA - EMBRAPA. Centro Nacional de Pesquisa de Solos. Sistema brasileiro de classificação de solos. Brasília: 1999. 412 p.

EVANS, S. P. et al. Nitrogen application influences the critical period for weed control in corn. Weed Sci., v. 51, p. $408-417,2003$.

INFORMAÇÕES Técnicas para a Safra 2006: Trigo e Triticale, 28., REUNIÃO DA COMISSÃO SUL BRASILEIRA DE PESQUISA DE TRIGO E TRITICALE, REUNIÃO DA COMISSÃO CENTRO-SUL BRASILEIRA DE PESQUISA DE TRIGO E TRITICALE, 21., Passo Fundo, 2006. Reunião... Passo Fundo: Embrapa Trigo, 2006. 74 p.

KOZLOWSKI, L. A. Período crítico de interferência das plantas daninhas na cultura do milho baseado na fenologia da cultura. Planta Daninha, v. 20, n. 3, p. 365-372, 2002.

LARCHER, W. Ecofisiologia vegetal. São Carlos: Rima, 2000. $531 \mathrm{p}$.
MEROTTO JR, A. Processo de afilhamento e crescimento de raízes de trigo afetadas pela resistência do solo. 1995. 114 f. Dissertação (Mestrado em Fitotecnia) Universidade Federal do Rio Grande do Sul, Porto Alegre, 1995.

RADOSEVICH, S.; HOLT, J.; GHERSA, C. Weed ecology: implications for vegetation management. 2.ed. New York: Wiley, 1997. 589 p.

SILVA, M. R. M.; DURIGAN, J. C. Períodos de interferência das plantas daninhas na cultura do arroz de terras altas. I - Cultivar IAC 202. Planta Daninha, v. 24, n. 4, p. 685-694, 2006.

VELINI, E. D. Interferências entre plantas daninhas e cultivadas: In: Avances en manejo de malezas en la producción agrícola y florestal. Santiago del Chile: PUC/ ALAM, 1992. p. 41-58.

VIDAL, R. A.; FLECK, N. G.; MEROTTO JR., A. Período anterior ao dano no rendimento econômico (PADRE): nova abordagem sobre os períodos de interferência entre plantas daninhas e cultivadas. Planta Daninha, v. 23, n. 3, p. 387396, 2005. 